\title{
Probing the composition of Plasmodium species contained in malaria infections in the Eastern region of Ghana
}

Linda Eva Amoah ${ }^{1,2^{*}}$ (D), Dickson Donu ${ }^{1}$, Benjamin Abuaku ${ }^{3}$, Colins Ahorlu ${ }^{3}$, Daniel Arhinful ${ }^{3}$, Edwin Afari $^{4}$, Keziah Malm ${ }^{5}$ and Kwadwo Ansah Koram²,3

\begin{abstract}
Background: Asymptomatic falciparum and non-falciparum malaria infections are major challenges to malaria control interventions, as they remain a source of continual infection in the community. This becomes even more important as the debate moves towards elimination and eradication. This study sought to quantify the burden of Plasmodium malaria infection in seven communities in the Eastern Region of Ghana.

Methods: The cross-sectional study recruited 729 participants aged 85 years old and below from 7 closely linked communities. Finger pricked blood was used to prepare thick and thin blood smears as well as spot filter paper and an histidine rich protein 2 (HRP2) rapid diagnostic test kit (RDT). Genomic DNA was extracted from the filter paper dry blood spot (DBS) and used in PCR to amplify the Plasmodium 18S rRNA gene using species specific PCR.

Results: $96.6 \%$ of the participants were identified as afebrile, with axillary temperatures below $37.5^{\circ} \mathrm{C}$. PCR identified $66 \%$ of the participants to harbor malaria parasites, with 9 P. malariae and 7 P. ovale mono-infections accounting for $2.2 \%$ and $P$. falciparum combined with either 36 P. malariae or 25 P. ovale infections, accounting for $13.3 \%$. Parasite prevalence by microscopy (32\%) was similar to the RDT positivity rate (33\%). False positive RDT results ranged from $64.6 \%$ in children aged between 5 and 9 years to $10 \%$ in adults aged 20 years and above. No significant differences were observed in falciparum and non-falciparum parasite carriage at the community level, however young adults aged between 15 and 19 years had the highest prevalence (34.8\% (16/46)) of $P$. falciparum and $P$. malariae parasite carriage whilst children aged between 5 and 9 years had the highest level $(11.4 \%(14 / 123))$ of $P$. ovale carriage.

Conclusion: The high rate of misidentification of non-falciparum parasites and the total absence of detection of $P$. ovale by microscopy suggests that more sensitive malaria diagnostic tools including molecular assays are required to accurately determine the prevalence of carriers of non-falciparum parasites and low density P. falciparum infections, especially during national surveillance exercises. Additionally, malaria control interventions targeting the non-falciparum species $P$. malariae and $P$. ovale parasites are needed.
\end{abstract}

Keywords: Plasmodium, Malariae, Ovale, Falciparum, RDT, Submicroscopic

\footnotetext{
* Correspondence: lamoah@noguchi.ug.edu.gh

${ }^{1}$ Immunology Department, Noguchi Memorial Institute for Medical Research,

University of Ghana, Accra, Ghana

${ }^{2}$ West Africa Center for Cell biology of Infectious Pathogens (WACCBIP),

College of Basic and Applied Sciences, University of Ghana, Accra, Ghana

Full list of author information is available at the end of the article
}

(c) The Author(s). 2019 Open Access This article is distributed under the terms of the Creative Commons Attribution 4.0 International License (http://creativecommons.org/licenses/by/4.0/), which permits unrestricted use, distribution, and reproduction in any medium, provided you give appropriate credit to the original author(s) and the source, provide a link to the Creative Commons license, and indicate if changes were made. The Creative Commons Public Domain Dedication waiver (http://creativecommons.org/publicdomain/zero/1.0/) applies to the data made available in this article, unless otherwise stated. 


\section{Background}

Malaria, a parasitic disease caused in humans by five different species of the Plasmodium genus namely $P$. falciparum, $P$. malariae, P. ovale, $P$. vivax and $P$. knowlesi, remains a devastating public health problem in the tropical and subtropical regions worldwide [1]. The burden of malaria in Ghana remains high, despite the decrease in malaria related deaths from 2985 to 1264 in 2016 [2]. Notwithstanding the slowdown in the prevalence of symptomatic malaria [1], afebrile carriage of malaria parasites is a huge problem in a number of malaria endemic countries, mainly because the parasite carriers do not exhibit any of the clinical symptoms of malaria and are thus untreated [3]. Since gametocytes, the transmissible forms of the malaria parasite are produced at each erythrocytic cycle of the parasite these asymptomatic carriers continuously serve as transmission reservoirs [4] until they are cured of their infection.

In sub-Saharan African, the majority of malaria cases are caused by P. falciparum [1] with a minor but underestimated prevalence of other Plasmodium species [5]. In Ghana, $P$. falciparum is the most prevalent malaria causing species with a prevalence of $98 \%$ followed by $P$. malariae and $P$. ovale with prevalence of 2-9 and $1 \%$ respectively [6]. A study by Owusu et al in 2017, reported $P$. malariae prevalence of $12.7 \%$ in the Kwahu south Region of Ghana [5] as compared to the national P. malariae prevalence of 2-9\% [6]. The global distribution of $P$. malariae is sparse and variable, but is similarly endemic to West Africa, and other malaria endemic areas of the world [7-9]. Plasmodium malariae infections usually present as asymptomatic infections although some may result in clinical disease state $[10,11]$. The distribution of $P$. ovale is relatively limited but highly prevalent in tropical areas of Africa, including sub-Saharan Africa [12]. Plasmodium vivax is endemic in Asia but scarce in West Africa where the natives lack the Duffy antigen receptor for chemokines, an essential receptor for erythrocyte invasion by $P$. vivax [13]. Despite the widespread absence of the Duffy antigen receptor for chemokines in people from sub Saharan Africa a few recent reports of have identified $P$. vivax infections in some sub Saharan African countries including Mali and Nigeria [14-16].

In order to implement accurate measures for effective control and treatment of malaria the detection of all human Plasmodium species is important [17]. Recently, the definition of malaria elimination has been revised to include the interruption of the local transmission of all human malaria parasites [18], making it necessary that national control programs include surveillance of all malaria parasite species. However, due to the very low occurrence and parasite densities of $P$. malariae and $P$. ovale in sub-Saharan Africa where $P$. falciparum is endemic, only a few microscopists are able to correctly identify $P$. malariae and $P$. ovale infections [19]. This combined with the fact that most $P$. malariae and $P$. ovale infections present as mixed infections with $P$. falciparum $[11,20]$, likely contribute to the misdiagnosis and the very low reported prevalence of other Plasmodium species in populations where $P$. falciparum is highly endemic. Rapid diagnostic test kits for malaria have improved malaria diagnostics, however this is mainly true for $P$. falciparum infections where the histidine rich protein 2 (HRP2) antigen, which is specific for P. falciparum, is detected as these kits have the highest sensitivities compared with the other rapid diagnostic kits for malaria [21]. Detection of parasite lactate dehydrogenase and aldolase antigens can be used for the detection of all Plasmodium species either combined as a pan specific test kit (aldolase) or separately using species-specific lactate dehydrogenase, and these have higher specificities than the HRP2 based tests but are less sensitive [21].

In this study we sought to determine whether the contribution of $P$. malariae and $P$. ovale to the overall prevalence of malaria captured during multiple community surveys in the Eastern Region of Ghana could be accurately predicted without the use of molecular tools, especially as numerous community surveys are carried out without the use of molecular tools. As such we used microscopy, RDT and species-specific PCR to assess the prevalence and composition of malaria parasites carried by consenting individuals living in seven closely linked communities in the Eastern Region of Ghana.

\section{Methods}

\section{Characteristics of study site}

Pakro is one of the five sub-districts in the Akwapim South Municipal district of the Eastern Region of Ghana. Pakro comprises of 22 communities and has an estimated population of 7655 with and is located in the Akwapim South district in the Eastern region of Ghana [22]. There are two major rainy seasons, May to June and September to October. Parasite positivity rate by RDT in 2014 was $47.5 \%$ [23] and was identified by microscopy in 2017 to be $27.5 \%$ (unpublished data). The Pakro Health Center, which is the major Health Center serving the sub district and its surrounding communities is one of the 30 National Malaria Control Program sentinel sites monitoring malaria prevalence in Ghana. In 2017 adherence by the Pakro Health Center to the test treat and tract policy was $100 \%$ [24].

\section{Sample size and sampling method}

A minimum sample size of 675 individuals of all ages was computed for the study based on an estimated overall malaria prevalence of not less than $25 \%$ at $95 \%$ confidence interval, precision of $4 \%$ and design effect of 1.5 . 
A total of 15 compounds were randomly selected in each of the 7 communities to be able to achieve the minimum sample size based on an estimated average compound size of 6.4 in the Akwapim south district as per the 2010 population and housing census [22]. All residents in the selected compounds were eligible for testing.

\section{Study design}

This cross-sectional study was conducted in 7 (Amokope (AM), Ankwensu (AN), Anwensu (AW), Obosono (OB), Okomfo (OK), Towoboase (TO) and Yaw Boadi (YB)) out of 22 communities within the Pakro sub-district (Fig. 1), which were not included in an implementation research on malaria mass testing and treatment.

\section{Sample collection and processing}

Blood samples were obtained from a total of 729 afebrile individuals of all ages between October and November 2017. A finger prick sample of whole blood $(\sim 100 \mu \mathrm{l})$ was obtained from each individual. The blood was used to spot a Whatman No. 3 filter paper as well as SD Bioline HRP2 rapid diagnostic kit following the manufacturer's instruction. Thick and thin blood smears were also prepared for each individual. The blood stained
Whatman No. 3 filter papers were air-dried and individually stored in a desiccated Ziploc bag. The thin smears were fixed in methanol and stained, together with the thick smears, in 3\% Giemsa stain for 30-45 $\mathrm{min}$. The stained slides were rinsed, air-dried, and stored in plastic slide boxes for reading. All the microscopists were blinded of the RDT results.

\section{Malaria parasite identification and quantification by microscopy}

Parasite quantification was done using the thick smears whilst the thin smears were used for species identification. Plasmodium parasite density (PD) was estimated by multiplying the number of parasites identified per 200 white blood cells by 40 , given that there are approximately 8000 white blood cells/ $\mu$ l of blood. A thick smear was considered negative for Plasmodium parasites if no parasites were observed in 200 high-powered fields. Each blood smear was read by 2 independent microscopists. Discordant smear readings in terms of the presence of asexual/sexual stage parasites as well as species identification were re-examined by a third microscopist. Discordant results agreeing with the third reading were considered final.

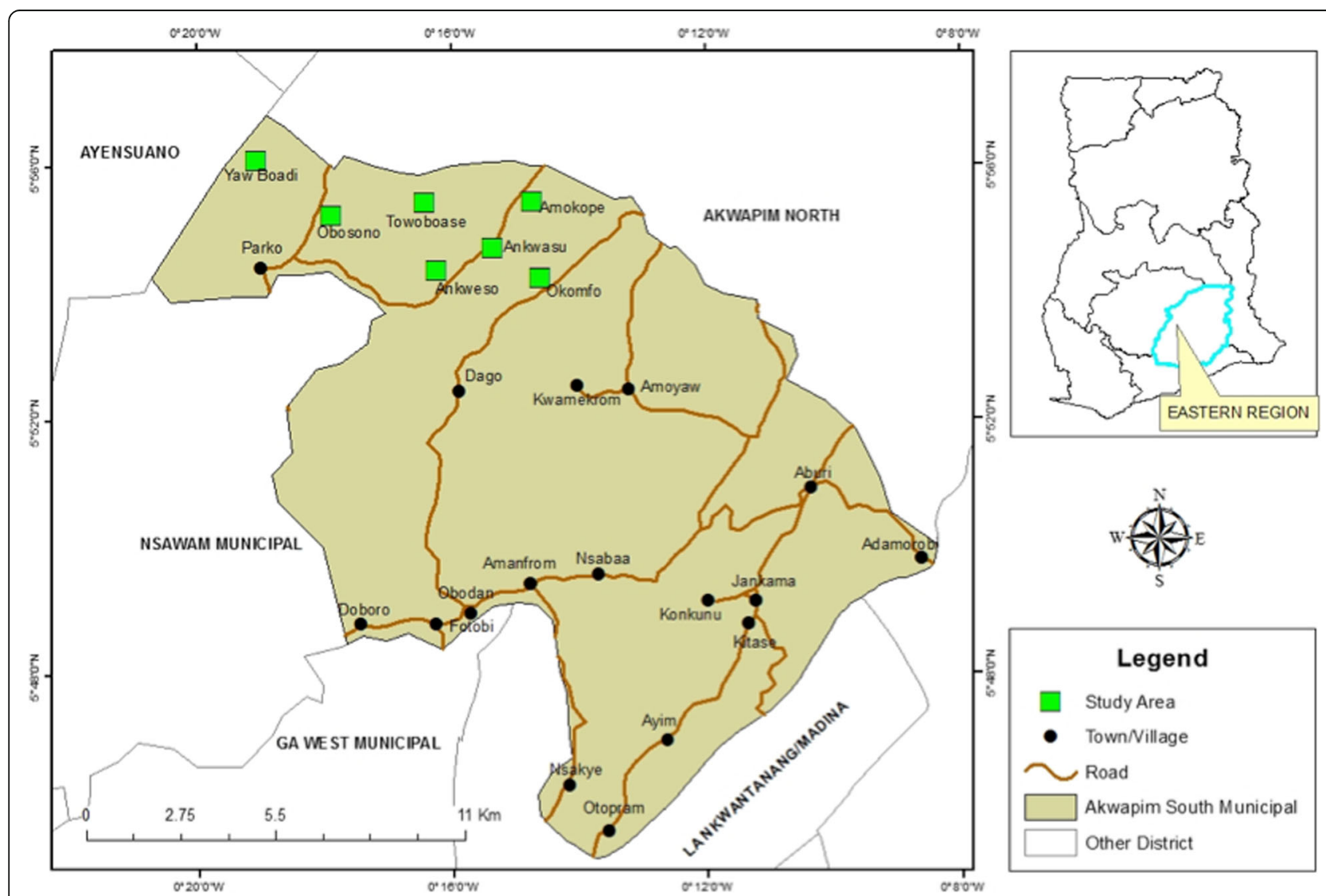

Fig. 1 A map of Ghana highlighting study sites located within the Eastern Region 


\section{DNA extraction}

Parasite DNA was extracted from the dried filter paper blood spots using the Chelex extraction method as previously described $[25,26]$. Each filter paper dried blood spot (DBS) was punched into a sterile $1.5 \mathrm{ml}$ microfuge tube containing $1 \mathrm{ml} 1 \mathrm{X}$ phosphate buffered saline (PBS) at a $\mathrm{pH}$ of 7.4 supplemented with $50 \mu \mathrm{l}$ of a $10 \%$ saponin solution. The tubes were incubated at $4{ }^{\circ} \mathrm{C}$ overnight. The DBS punches were washed for $30 \mathrm{~min}$ in ice cold PBS at $4{ }^{\circ} \mathrm{C}$ and the supernatant discarded. Finally, $60 \mu \mathrm{l}$ of freshly prepared 20\% Chelex-100 in 1X PBS and $140 \mu \mathrm{l}$ of distilled water was added to each tube. The tubes were then heated at $95^{\circ} \mathrm{C}$ for $10 \mathrm{~min}$ to extract the DNA from the samples. The tubes were finally centrifuged at $13000 \mathrm{rpm}$ for $6 \mathrm{~min}$ and $120 \mu \mathrm{l}$ of the supernatant transferred into a new sterile labeled $0.5 \mathrm{ml}$ microfuge tube. The DNA was stored at $-20^{\circ} \mathrm{C}$ or used immediately.

\section{Plasmodium species ( $P$. falciparum, $P$. malariae and $P$. ovale) identification}

Nested PCR was used to amplify unique regions of the $P$. falciparum, $P$. malariae and $P$. ovale $18 \mathrm{~s}$ rRNA gene from genomic DNA extracted from the samples using a previously described protocol [27] with little modifications. In the primary reaction, $80 \mathrm{nM}$ of the genus specific primers rPLU5 (forward) and rPLU6 (reverse) were used in a total reaction volume of $15 \mu \mathrm{l}$ made up of $5 \mu \mathrm{l}$ DNA template, $1 \mathrm{X}$ PCR buffer, $167 \mathrm{nM}$ dNTPs, $2.5 \mathrm{mM}$ $\mathrm{MgCl}_{2}$ and $1 \mathrm{U}$ of OneTaq DNA polymerase. In the secondary reaction (nest 2), the species-specific primers rFAL1/rFAL2 (133.33 nM), rMAL1/rMAL2 (333.33 nM) and rOVA1/rOVA2 $(333.33 \mathrm{nM})$ were used in separate $15 \mu \mathrm{l}$ reactions for the identification of $P$. falciparum, $P$. malariae and $P$. ovale respectively. The template for the secondary reaction was $0.5 \mu \mathrm{l}$ of the primary reaction product. Details of all the primers used are provided in Additional file 1: Table S1.

The primary and nested PCR reaction cycling conditions included an initial denaturation at $95^{\circ} \mathrm{C}$ for $5 \mathrm{~min}$ followed by 35 cycles a second denaturation at $94{ }^{\circ} \mathrm{C}$ for $30 \mathrm{~s}$, primer annealing step at $55^{\circ} \mathrm{C}$ (for primary) or $58^{\circ} \mathrm{C}$ (for nested) for $1 \mathrm{~min}$ and sequence extension at $68^{\circ} \mathrm{C}$ for $1 \mathrm{~min}$ and a final extension at $68^{\circ} \mathrm{C}$ for $5 \mathrm{~min}$.

The secondary PCR products were resolved on a $1 \%$ agarose gel pre-stained with ethidium bromide, which were subsequently visualized using the UV settings on a Vilbar gel documentation system.

\section{Data analysis}

Data were either considered as a complete dataset or grouped according to collection community or categorized into young children below 5 years, children between 5 and 9 years, older children between 10 to 14 years, young adults 15 to 19 years and adults (20 years and above). Prevalence of Plasmodium infections was calculated as the proportion of individuals that were identified as positive for the presence of parasites (either all parasite species or an individual species) in each community or age group category.

The Kruskal-Wallis test (GraphPad Prism ver 5) was used to determine significant differences between the median ages of the study participants in each community. GraphPad Prism ver 5 was also used to determine the mean PD and its standard error (SEM) in the different sites and cohorts. Descriptive statistics including frequency and Pearson Chi-Square analysis was used to identify significant differences between parasite prevalence in the different sites and cohorts (IBM SPSS ver 22). $P$ values of less than 0.05 were considered statistically significant.

\section{Results}

The study population comprised of 729 participants aged below 85 years (Table 1) recruited from 7 closely linked communities. The proportion of males in the study population ranged between $37 \%(17 / 46)$ in young adults between 15 years to 19 years and 60\% (74/123) in children between 5 years to 9 years (Table 1). A total of $3.4 \%(25 / 729)$ of the study participants were identified as febrile and had axillary temperatures of or above $37.5^{\circ} \mathrm{C}$. Children aged between 5 and 9 years had the highest prevalence of febrile cases $(5.6 \%)$ and adults $\geq 20$ years old had the least prevalence of febrile cases (2.4\%) (Table 1 ). There was no significant difference (Kruskal-Wallis test, $p=0.6621)$ in the median ages of the participants from all the 7 communities.

\section{Parasite prevalence \\ Rapid diagnostic test (RDT)}

About a third of the population sampled, 33.1\% (241/729), tested positive for P. falciparum using the HRP-2 RDT kit. Parasite positivity rates were significantly different (Pearson Chi-Square $=145.557, p=0.000$ ) across the five age groups with the lowest prevalence identified in adults 20 years old and above (13.8\% (51/369)) and highest prevalence $(64.2 \%(79 / 123))$ in children aged between 5 and 9 years old (Table 2). Parasite positivity rates were significantly higher in Obosono (Pearson Chi Square 6.494, $p=$ $0.039)$ with a rate of $41.5 \%(50 / 122)$ and lowest positivity rate was 23.7\% (18/76) in Amokope (Table 3).

\section{Microscopy estimation of parasite prevalence and species} Approximately a third $(233 / 729 ; 32.0 \%)$ of the participants were identified by microscopy to be positive for Plasmodium parasites. The agreement between first and second slide readings was approximately $96 \%$. Almost $99 \%(231 / 233)$ of the infections identified by microscopy 
Table 1 Demographic characteristics of study participants

\begin{tabular}{lllllll}
\hline & $<5$ yrs. (79) & $5-9 y r s .(123)$ & $10-14$ yrs. (112) & $15-19 y r s .(46)$ & 220 yrs. (369) & Total (729) \\
\hline Sex (M/F) & $40 / 39$ & $74 / 49$ & $58 / 54$ & $17 / 29$ & $160 / 207$ & $349 / 378$ \\
Febrile & $2(2.5)$ & $7(5.6)$ & $5(4.5)$ & $2(4.4)$ & $9(2.4)$ & $25(3.4)$ \\
\hline
\end{tabular}

$M$ male, $F$ female, yrs. years, Febrile, axillary temperature $\geq 37.5^{\circ} \mathrm{C}$

were single species infections, with $P$. falciparum accounting for $81.5 \%(190 / 231)$ and P. malariae accounting for $17.6 \%(41 / 232)$. Mixed species infections accounted for $0.85 \%(2 / 233)$ of the microscopic density infections. No sample was identified as containing $P$. ovale by microscopy.

Parasite prevalence was significantly different amongst the five different age groups (Pearson Chi-Square = 85.428, $p=0.000$ ) and ranged from $17.6 \%$ in the adults aged 20 and above to $54.5 \%$ in children aged 5-9 years old. Gametocyte carriage amongst the different age groups was significantly different (Pearson Chi-Square $=$ $12.255, p=0.016$ ). Gametocyte carriage was highest in the young adults $(8 \%(9 / 112))$, followed by the young children $(7.6 \%(6 / 79))$ and least in the adult (20 years and above) group (1.9\% (7/369))(Table 2).

Parasite carriage was, similar across the seven sites (Pearson Chi-Square 10.450, $p=0.107$ ). The highest $40.4 \%$ (38/94) and lowest 20.4\% (11/54) prevalence of people with microscopic densities of parasites were recorded in Okomfo and Yaw Boadi respectively (Table 3). Similarly, gametocyte carriage amongst the sites was similar and ranged from 0\% in Amokope to 7.4\% (9/122) in Obosono.

\section{Molecular (polymerase chain reaction, $P C R$ ) estimation of parasite prevalence and species}

Amplification of the Plasmodium 18SrRNA gene from the extracted DNA identified 66\% (481/729) samples as positive for Plasmodium parasites (Tables 2 and 3). Out of the Plasmodium positive samples, 417 (86.6\%) were mono-infections, with $P$. falciparum mono-infections accounting for $96.2 \%$ of the total (401/417) and P. malariae and P. ovale each contributing $2.1 \%(9 / 417)$ and $1.7 \%$ (7/417) to the mono-infections respectively. Combined, $P$. falciparum infections (mono and mixed) determined by PCR accounted for $96.67 \%$ (465/481) of the total Plasmodium positive samples. Multispecies-infections constituted $13.3 \%(64 / 481)$ of the infected samples, of which $P$. falciparum and $P$. malariae co-infections represented 56\% (36/64) and $P$. falciparum and $P$. ovale represented $39 \%(25 / 64)$ of multi-infected samples. There were $5 \%(3 / 64)$ of the samples that tested positive for all three species, $P$. falciparum, $P$. malariae and $P$. ovale species. No co-infection of $P$. malariae and $P$. ovale in the absence of $P$. falciparum was identified (Fig. 2).

Out of the 465 samples that tested positive for P. falciparum by PCR, 251 (54\%) and 290 (62.4\%) tested negative (false negative) by RDT and microscopy ( $P$. falciparum) respectively; 175 samples tested positive by both PCR and microscopy (P. falciparum), 214 samples tested positive by both PCR and RDT (Table 4) and 132 samples tested positive by all $3 P$. falciparum specific tests (Fig. 3).

Taking PCR as the reference, false positive results (samples that were negative by $P$. falciparum specific

Table 2 Age stratified prevalence of malaria in study participants

\begin{tabular}{lllllll}
\hline & $<5$ yrs. 79 & $5-9 y r s .123$ & $10-14$ yrs. 112 & $15-19$ yrs. 46 & $\geq 20$ yrs. 379 & Total 729 \\
\hline RDT & $38(48.1)$ & $79(64.2)$ & $60(53.6)$ & $13(28.3)$ & $51(13.5)$ & $241(33)$ \\
Microscopy Positives (All Species) & $30(38)$ & $67(54.5)$ & $58(51.8)$ & $13(38.2)$ & $65(17.2)$ & $233(32)$ \\
Microscopy Mono & $30(100)$ & $67(100)$ & $57(98.3)$ & $12(92.3)$ & $65(100)$ & $231(99)$ \\
Microscopy Multi & $0(0)$ & $0(0)$ & $1(1.7)$ & $1(7.7)$ & $0(0)$ & $2(0.86)$ \\
Gametocytes & $6(7.6)$ & $8(6.5)$ & $9(8.04)$ & $2(4.3)$ & $7(1.9)$ & $32(4.4)$ \\
PD mean & 9591.2 & 3837.4 & 3455.8 & 150.9 & 507.6 & 334.6 \\
PD range (min - max) & $47.7-113,462$ & $16-68,000$ & $15.1-95,555.6$ & $16-553.4$ & $3.8-9014.6$ & $3.8-113,462$ \\
PCR Positive (All Species) & $43(54.4)$ & $100(81.3)$ & $99(88.4)$ & $34(73.9)$ & $204(53.8)$ & $481(66)$ \\
Pf & $41(95.4)$ & $97(97.0)$ & $98(99)$ & $34(100)$ & $194(51.2)$ & $465(96.7)$ \\
Pm & $1(2.3)$ & $15(15.0)$ & $16(16.2)$ & $1(2.9)$ & $15(7.4)$ & $48(10)$ \\
Po & $5(11.6)$ & $14(14.0)$ & $5(5.1)$ & $32.9)$ & $10(5.2)$ & $35(7.3)$ \\
PCR Mono & $39(90.7)$ & $75(75.0)$ & $81(81.8)$ & $32(92.1)$ & $189(92.7)$ & $417(86.7)$ \\
PCR Multi & $4(9.3)$ & $25(25.0)$ & $18(18.2)$ & $2(5.9)$ & $15(7.4)$ & $64(13.3)$ \\
\hline
\end{tabular}

Mono single parasite species infection, multi multiple parasite species infection, RDT PfHRP2 based malaria rapid diagnostic test, $P D$ parasite density (parasites/ $\mu$ ) of blood, Pf Plasmodium falciparum, Pm Plasmodium malariae, Po Plasmodium ovale, yrs. years. Values are written as counts (\%) 
Table 3 Parasite prevalence by RDT, microscopy and PCR

\begin{tabular}{|c|c|c|c|c|c|c|c|c|}
\hline & OB (122) & TB (132) & OK (94) & AK (117) & AW (134) & AM (76) & YB (54) & Total (729) \\
\hline PCR Positive (\%) & $87(71.3)$ & $74(56.1)$ & $62(66.0)$ & $81(69.2)$ & $91(67.9)$ & $46(60.5)$ & $40(74.1)$ & $481(66.0)$ \\
\hline < 5 yrs. (\%) & $8 / 12(66.7)$ & 4/14 (28.6) & $5 / 7(71.4)$ & 12/17 (70.6) & 5/11 (45.5) & 5/11 (45.5) & 4/7 (57.1) & 43/79 (54.4) \\
\hline 5-9yrs. (\%) & 19/25 (76) & $17 / 20(85)$ & 12/17 (70.6) & 14/16 (87.5) & $22 / 27$ (81.5) & 8/9 (88.9) & 8/9 (88.9) & 100/123 (81.3) \\
\hline 10-14 yrs. (\%) & 19/21 (90.5) & 23/24 (95.8) & 15/19 (78.9) & $12 / 14(85.7)$ & 21/ 23 (91.3) & $2 / 3(66.7)$ & $7 / 8$ (87.5) & $99 / 112(88.4)$ \\
\hline 15-19yrs. (\%) & 7/9 (77.8) & 3/9 (33.3) & 6/8 (75) & $5 / 5(100)$ & 10/12 (83.3) & 0/0 & $3 / 3(100)$ & $34 / 46$ (73.9) \\
\hline$\geq 20$ yrs. (\%) & $34 / 55(61.8)$ & $27 / 65$ (41.5) & 24/43 (55.8) & 38/65 (58.5) & 33/61 (54.1) & 31/53 (58.3) & 18/27(66.7) & 205/369 (55.6) \\
\hline \multicolumn{9}{|l|}{ Microscopy } \\
\hline Positive (\%) & $42(34.4)$ & $48(36.4)$ & $38(40.4)$ & 37 (31.6) & $38(28.4)$ & $19(25.0)$ & $11(20.4)$ & $233(32.0)$ \\
\hline Mono Pf & $36(29.5)$ & $33(25.0)$ & $33(35.1)$ & $30(25.6)$ & $35(26.1)$ & $19(25.0)$ & $6(11.1)$ & $192(26.3)$ \\
\hline Mono Pm & $6(4.9)$ & 15 (11.4) & $6(6.4)$ & $8(6.8)$ & $3(2.2)$ & $0(0)$ & $5(9.3)$ & $43(5.9)$ \\
\hline Mono Po & $0(0)$ & $0(0)$ & $0(0)$ & $0(0)$ & $0(0)$ & $0(0)$ & $0(0)$ & $0(0)$ \\
\hline Multispecies (\%) & $0(0)$ & $0(0)$ & $1(1.1)$ & $1(0.9)$ & $0(0)$ & $0(0)$ & $0(0)$ & $2(0.3)$ \\
\hline Febrile $\left(\geq 37.5^{\circ} \mathrm{C}\right)$ & $2(1.6)$ & $4(3.0)$ & $2(2.1)$ & $10(8.5)$ & $2(1.5)$ & $5(6.6)$ & $0(0)$ & $25(3.4)$ \\
\hline PD (p/ul) Mean (SEM) & $1685(622.3)$ & $2251(1425)$ & 3724 (2519) & 3067 (979.7) & $2575(1043)$ & $6322(5955)$ & $11,723(7631)$ & 3349 (823.6) \\
\hline PD $(p / \mu l)$ Min - max & $14-17,359$ & $16-68,000$ & $15-95,556$ & $16-23,360$ & $15-31,849$ & $4-113,462$ & $16-68,000$ & $4-113,462$ \\
\hline RDT (\%) & $50(41.0)$ & $46(34.8)$ & $36(38.3)$ & $32(27.6)$ & $44(32.8)$ & $18(23.7)$ & $15(28.9)$ & 241 (33.1) \\
\hline
\end{tabular}

OB Obosono, TB Towoboase, OK Okomfo, AK Akwensu, AW Awensu, AM Amokope, YB Yaw Boadi, RDT PfHRP2 based malaria rapid diagnostic test positive samples, $P D$ parasite density per $\mu$ l blood, min minimum, max maximum, Mono single species infection, Febrile, axillary temperature ( $\geq 37.5^{\circ} \mathrm{C}$ ). PCR positive and microscopy positive samples include all Plasmodium species

PCR) accounted for $11.2 \%(27 / 241)$ and $8.9 \%(17 / 192)$ of the RDT and P. falciparum positive microscopy samples respectively (Table 4).

False positive microscopy results were most (13.8\% (8/ 58)) prevalent in older children aged between 10 and 14 years old and least $(2.4 \%(1 / 41))$ prevalent in young adults aged 15 to 19 years old. Whilst submicroscopic densities of $P$. falciparum estimated by PCR were most

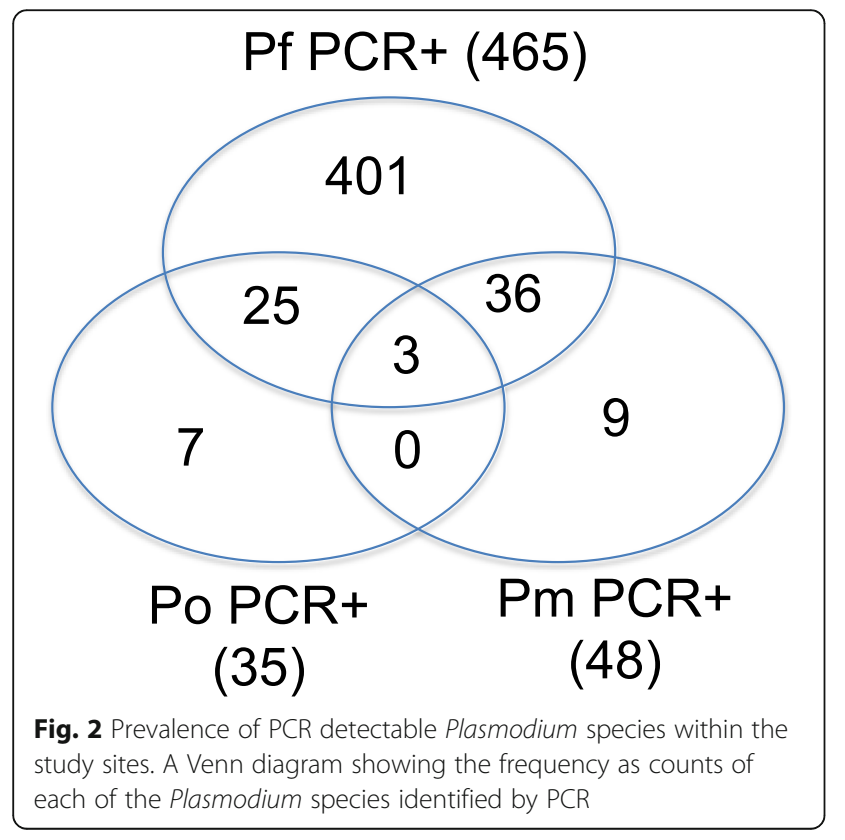

(81.7\% (58/71)) prevalent in older children aged between 15 and 19 years old and least $(35.2 \%(19 / 54))$ prevalent in young children aged 4 years and below.

False positive RDT results were most $(21.1 \%(8 / 38))$ and least $(0 \%(0 / 13))$ prevalent in children aged 4 years old and below and young adults aged 15 to 19 years old respectively. Whilst false negative RDT results were most $(78.8 \%(41 / 52))$ and least $(26.8 \%(11 / 41))$ prevalent in older children aged between 10 and 14 years old and young children aged 4 years and below respectively.

Out of the 48 samples that tested positive for P. malariae by PCR, only 11 were identified by microscopy, whilst 32 samples that were identified as positive for $P$. malariae by microscopy were negative for $P$. malariae by PCR.

Parasite prevalence estimated by PCR across the five age groupings was significantly different for all the three Plasmodium species identified (Pearson Chi-Square

Table 4 Sensitivity and specificity of Plasmodium falciparum parasite detection

\begin{tabular}{lll}
\hline & Pf PCR+ (465) & Pf PCR- (264) \\
\hline RDT+ (241) & 214 & 27 \\
RDT- (488) & 251 & 237 \\
Pf Micro+ (192) & 175 & 17 \\
Pf Micro- (537) & 290 & 247
\end{tabular}

Pf Plasmodium falciparum, micro microscopy, RDT PfHRP2 based malaria rapid diagnostic test, + , positive; - , negative. The numbers in the table represent frequency in counts 


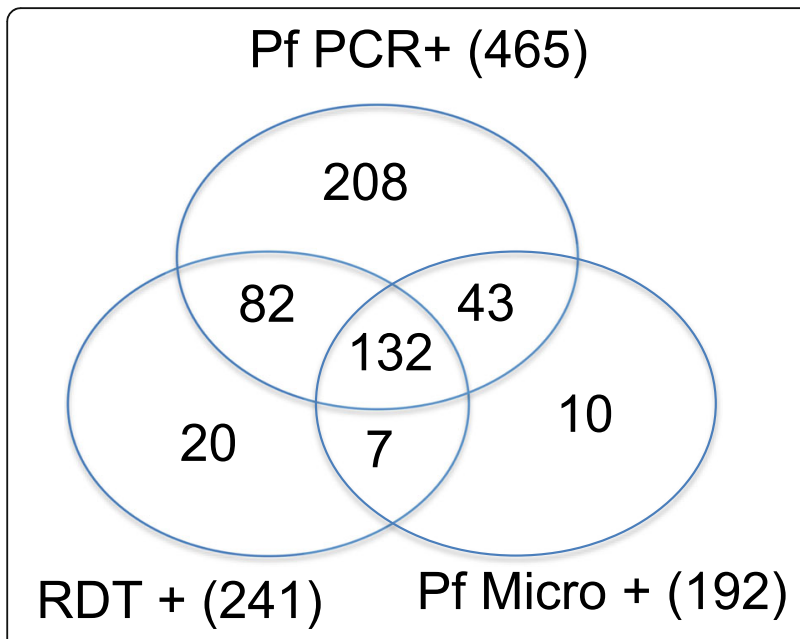

Fig. 3 Prevalence of $P$. falciparum detected by varying diagnostic tools. A Venn diagram showing the detection of $P$. falciparum by microscopy, RDT and $P$. falciparum specific PCR

65.364, $p=0.000$ (P. falciparum); 25.991, $p=0.000$ ( $P$. malariae); 16.311, $p=0.003$ (P. ovale)). Plasmodium falciparum and $P$. malariae was least prevalent in the young children aged below 5 years old and highest in the older children aged between 9 and 14 years and $P$. ovale most prevalent in the children (5-9 years) and least in the two adult groups (2.2\% in young adults and $2.7 \%$ in adults) (Table 3). However, across the seven sites, there was no significant difference in the distribution of $P$. falciparum, but significant differences were identified in the distribution of $P$. malariae (Pearson Chi-Square 16.435, $p=0.012$ ) and $P$. ovale (Pearson Chi-Square 15.869, $p=0.014$ ) (Fig. 4). The prevalence of parasite carriers was much higher when estimated by PCR compared to estimates by microscopy (Fig. 5). There were $62.4 \%(290 / 465)$ of the P. falciparum positive samples that were not detected as $P$. falciparum by microscopy. Molecular (PCR) identification increased the prevalence of $P$. malariae by $0.7 \%$ (5/729), however, P. falciparum was misdiagnosed as $P$. malariae in $7.7 \%(46 / 465)$ of the samples and $P$. malariae was misdiagnosed in $31.5 \%$ $(15 / 48)$ of the samples and identified as $P$. falciparum by microscopy. The prevalence of $P$. ovale increased from 0 to $4.8 \%$ (35/729), similarly, $62.9 \%(22 / 35)$ of the P. ovale samples were misdiagnosed and identified as $P$. falciparum $[86.3 \%(19 / 22)]$ or as P. malariae $[13.6 \%(3 / 22)]$ by microscopy (Fig. 5).

\section{Discussions}

In most malaria endemic countries in the World Health Organization Africa Region, P. falciparum is the major malaria parasite and represents close to $90 \%$ or more of

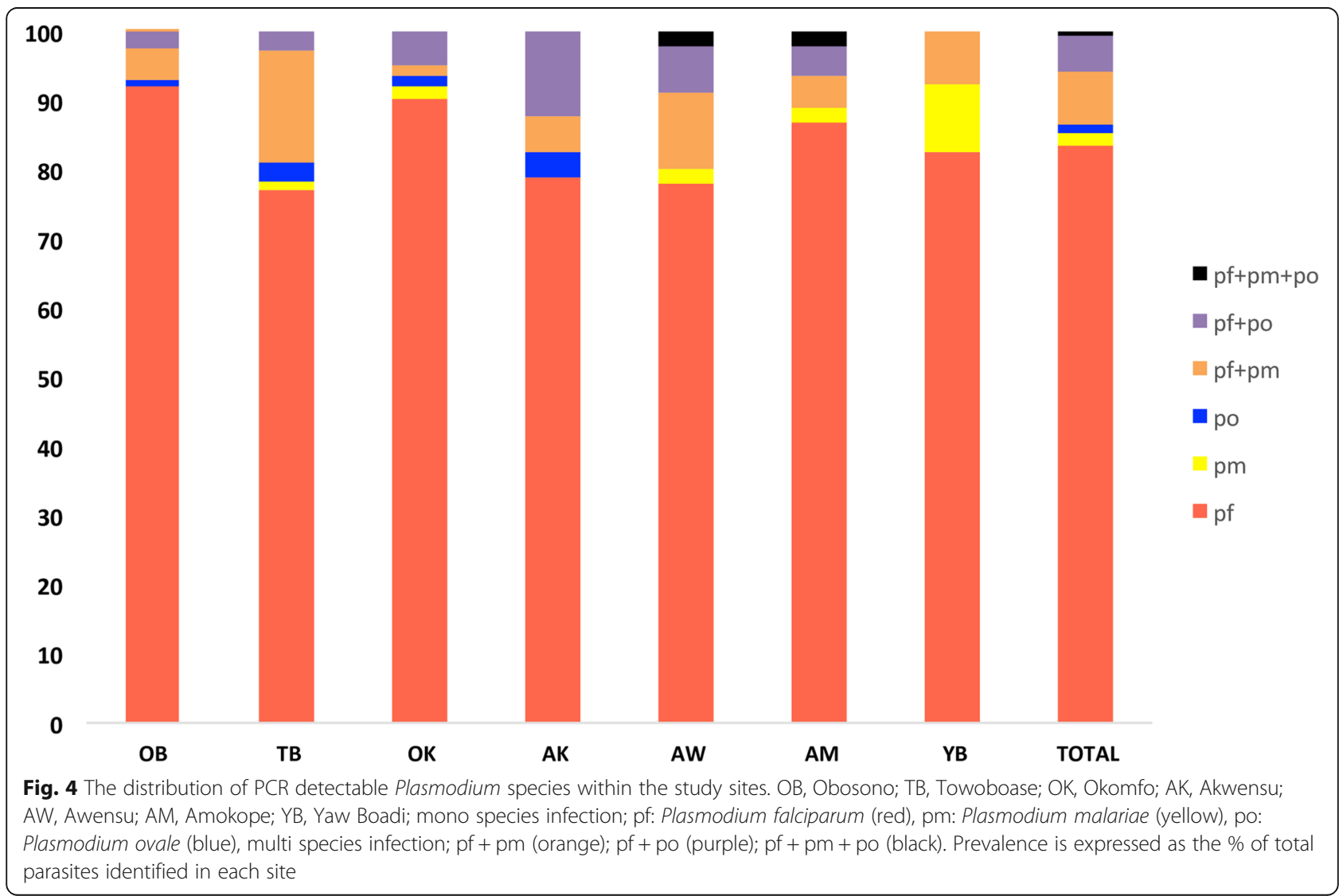



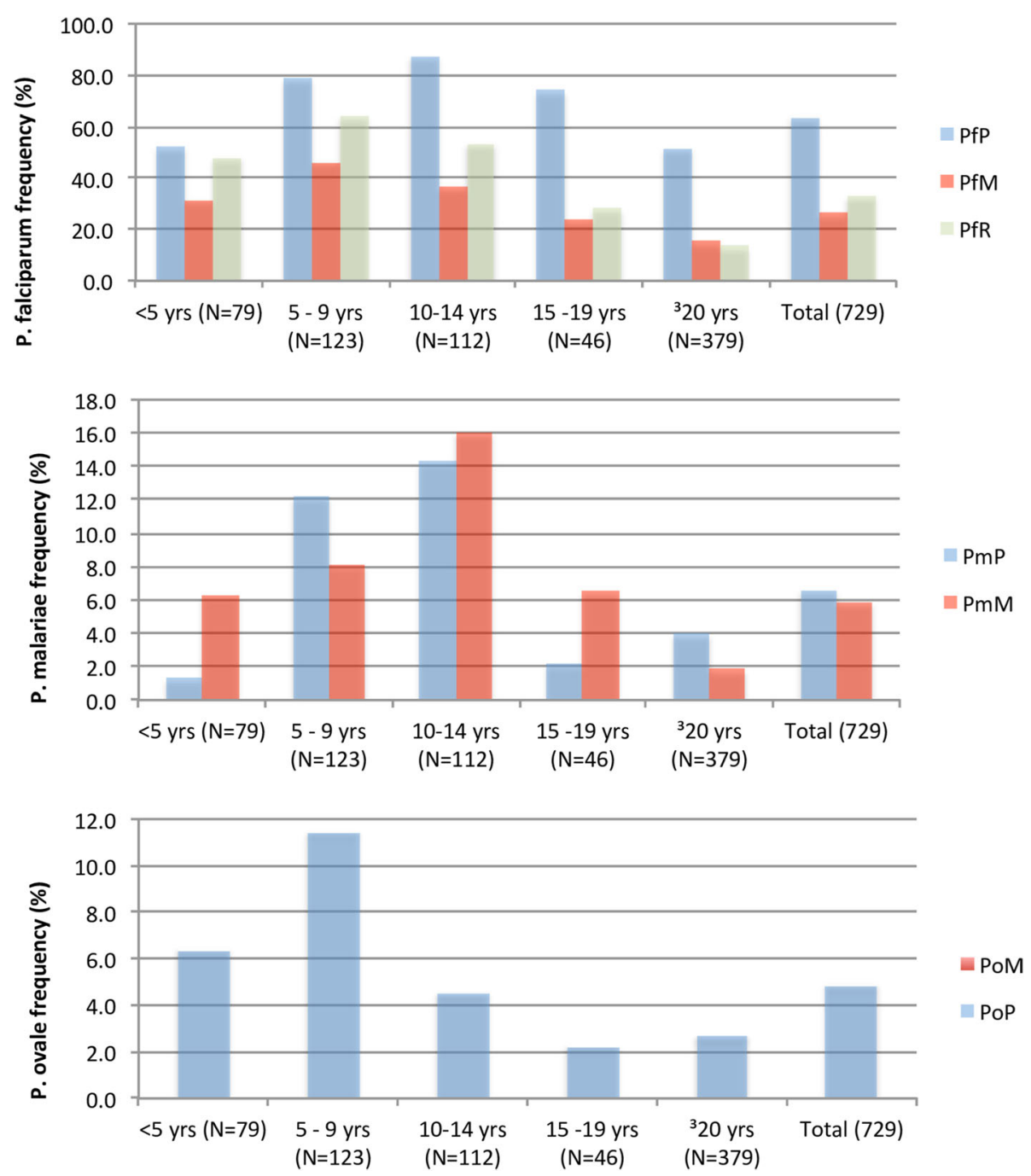

Fig. 5 Comparison of diagnostic tools. A bar graph showing the prevalence of $P$. falciparum (Pf), P. malariae (Pm) and P. ovale (Po) as estimated by species specific PCR (P), microscopy (M) and RDT (R). values shown represent frequency expressed as a \% of the total number of samples (729)

the total malaria parasite population [1]. The 2018 world malaria report estimated P. falciparum to represent $100 \%$ of the total parasite population in Ghana [1]. Similarly, the National Malaria Control Program, Ghana uses parasitaemia in referring to the presence of malaria parasites, without the distinction between the various Plasmodium species [2, 28-30]. Coinfections of $P$. malariae or $P$. ovale with $P$. falciparum have been reported to lower the total parasite density of an infection [10] and also increase $P$. falciparum gametocyte prevalence [31]. Very few reports have determined the distribution or prevalence of non-falciparum parasites [5, 32], making this study very essential not only to fill a knowledge gap but also to inform policy on the need for sensitive tools to enable the identification of the under reported prevalence of $P$. malariae and $P$. ovale parasites.
The prevalence of Plasmodium carriers was generally high in this study with a PCR estimated average of $66 \%$ and a microscopy average of $32 \%$. The increased prevalence determined by PCR is expected as microscopy is known to underestimate parasite prevalence, especially at low parasite densities [33]. The high prevalence of submicroscopic infections identified in this study as well as other studies [33-35] is a big challenge to malaria control in Ghana as the Test Treat and Track program is based on the microscopic detection of malaria parasites. This suggests that even if the program is $100 \%$ effective, malaria transmission will still be very high as half of the infected population is afebrile, thus not identified and treated. In this study, the prevalence $P$. malariae estimated by microscopy and PCR were similar, which was contrary to the differences between $P$. falciparum and $P$. ovale estimates, which were much higher by PCR when 
compared with microscopy. One main reason for the disparity was the high number of $P$. falciparum samples that were misclassified as $P$. malariae by the microscopists. Misclassification of Plasmodium species is particularly common in countries with a low prevalence of non-falciparum malaria primarily because of infrequent encounter by the microscopist and the subsequent low ability to identify morphological differences amongst the various Plasmodium species [36]. The World Health Organization recommends that uncomplicated infections harboring $P$. falciparum and $P$. malariae are treated with the same dose of artemisinin combination therapy [17] as such, a misclassification of $P$. malariae for $P$. falciparum and vice versa may not result in severe outcomes. However, due to the requirement of a radical cure agent such as Primaquine to clear $P$. ovale hypnozoites the treatment regimen is artemisinin combination therapy + Primaquine [17], thus misclassifications of $P$. ovale with $P$. falciparum could lead to severe $P$. ovale infections.

Children under the age of 5 years are considered to be the most vulnerable groups [1], however, in this study, children under 5 years did not have the highest prevalence of infection, although they had the highest parasite load. This observation supports the results from an earlier study conducted on adults and children with asymptomatic malaria infections living in Northern Ghana [35] as well as another study conducted on children from Ivory Coast and Mauritania [37]. A contrary finding has been reported in a study conducted on symptomatic malaria patients, where the parasite load in children under 5 was lower than those of older children [38]. The disparity in these findings could be due to the use of volunteers with different malaria status and suggests that young children with afebrile malaria infections may be able to withstand higher parasite densities compared with their symptomatic counterparts and older age groups. Older children aged between 10 and 14 years old were identified as having the highest prevalence of afebrile Plasmodium carriers, including both $P$. falciparum asexual and gametocyte as well as $P$. malariae parasite carriage. High gametocyte carriage in the group with the highest prevalence of both $P$. falciparum and $P$. malariae could be due to intra-host competition, which is known to enhance $P$. falciparum gametocyte production [31]. An earlier report on asymptomatic carriers in Kenya also identified children below the age of 15 years to harbor the highest levels of $P$. malariae than the older population, which is similar to the findings in this study [39]. All three groups of children in this study are more likely to enhance malaria transmission due to the high prevalence of microscopic densities of gametocytes carried by the group members. Although membrane feedings assays were not conducted in this study, other studies have found that high-density gametocyte infections contribute more to malaria transmission than low-density (sub microscopic) gametocyte infections [40].

In this study, age influenced the false positive RDT rates, with children having much higher false positive rates than the adult group. One main reason why the three groups of children exhibited high false positive rates could be because children generally have more incidents of clinical malaria as well as have higher density infections [41], which when treated would result in high levels of HRP2 antigen and a resultant longer duration of HRP2 antigen persistence that causes false positive RDT result [42]. Persistence of HRP2 antigen that is responsible for majority of false positive HRP2 RDT results is concentration dependent [43] and will take longer to clear after the treatment of high-density infections $[44,45]$. False negative RDT results have also been associated with the presence of parasites with deletions in the Pfhrp2 gene $[46,47]$ or the presence of very high parasite densities that result in high concentrations of HRP2 antigen and a subsequent prozone effect [48]. False negative microscopy results are mainly due to the presence of submicroscopic densities of parasites, which are very common in asymptomatic infections [33]. Though there might be a possibility of false positive PCR results due to either contaminations during sample processing and amplification [49], nucleic acid amplification methods such as PCR has been recommended by the World Health Organization to be used to provide more accurate prevalence measurements during surveillance exercises as well as for malaria parasite detection in low transmission settings [50].

Even though afebrile parasite carriage was significantly affected by age, Plasmodium parasite carriage was similar in the seven closely linked communities. This suggests that although similar malaria control interventions would be effective in closely linked communities, interventions should be age group specific. There are a number of malaria control interventions that are targeted to protect children below the age of 5 years, one of the most vulnerable groups with respect to malaria from exposure to the malaria parasite [1]. The results from this study suggest that those interventions are effective as only a small fraction of the children below 5 years old living in the communities surveyed carried malaria parasites.

Previous reports on the distribution and prevalence of non-falciparum malaria parasites in Ghana vary from less than $1 \%$ to more than $12 \%$ across different regions of the country $[5,51,52]$, with no reports of the presence of $P$. vivax in Ghana to date [5]. In order to obtain a more accurate measure of the nationwide distribution and prevalence of non-falciparum malaria in Ghana, it is necessary that nationwide molecular surveys of all 
human malaria parasites be conducted on a regular basis. This will help determine the geographic distribution and prevalence of non-falciparum malaria parasites, especially $P$. ovale and decide whether there is a need to implement a revision to the national malaria treatment policy to incorporate a treatment regimen for $P$. ovale, which is presently absent in Ghana.

\section{Conclusion}

The high rate of misidentification of non-falciparum parasites and the total absence of detection of $P$. ovale by microscopy suggests that more sensitive malaria diagnostic tools including molecular assays are required to accurately determine the prevalence of carriers of nonfalciparum parasites and low-density $P$. falciparum infections, especially during national surveillance exercises. Additionally, malaria control interventions targeting the non-falciparum species $P$. malariae and $P$. ovale parasites are needed.

\section{Supplementary information}

Supplementary information accompanies this paper at https://doi.org/10. 1186/s12889-019-7989-1.

Additional file 1: Table S1. List of primers and their properties

\section{Abbreviations}

AM: Amokope; AN: Ankwensu; AW: Anwensu; DBS: Dried blood spot; OB: Obosono; OK: Okomfo; P. falciparum: Plasmodium falciparum; P. malariae: Plasmodium malariae; P. ovale: Plasmodium ovale; P. vivax: Plasmodium vivax; PBS: Phosphate buffered saline; PCR: Polymerase chain reaction; PD: Parasite density; RDT: Rapid diagnostic test; TO: Towoboase; YB: Yaw Boadi

\section{Acknowledgements}

The authors are grateful to the study participants for volunteering to be a part of the study and to Mr. Richard Adade, GIS \& Remote Sensing Unit, Department of Fisheries and Aquatic Sciences, University of Cape Coast, Ghana for creating the Map used in Fig. 1. We are also grateful to the Malaria Centre of Excellence at the University of Ghana for funding and all members of the Malaria Centre of Excellence, University of Ghana.

\section{Authors' contributions}

LEA, BA, CA, DA, KM, EA and KAK designed the study; BA and CA collected the samples, LEA and DD performed the experiments; LEA, DD, BA, CA, DA, KM, EA and KAK wrote the manuscript; LEA performed the statistical analysis. All authors read and approved the final manuscript.

\section{Funding}

This work was funded by the Malaria Centre of Excellence, University of Ghana. The funder had no role in the design of the study and the collection, analysis, and interpretation of data and in writing the manuscript.

\section{Availability of data and materials}

The datasets used and/or analysed during the current study available from the corresponding author on reasonable request.

\section{Ethics approval and consent to participate}

Ethical approval for the study was obtained from the Institutional Review Board of the Noguchi Memorial Institute for Medical Research (IRB Approval \#: 009/15-16). Community engagement was conducted during which the aims and objectives of the study were explained to the entire population. Willing individuals provided written informed consent, assent and parental consent for minors prior to being recruited into the study.
Consent for publication

Not applicable.

\section{Competing interests}

CA is an Associate editor for the Global Health section of BMC Public Health.

\section{Author details}

${ }^{1}$ Immunology Department, Noguchi Memorial Institute for Medical Research, University of Ghana, Accra, Ghana. ${ }^{2}$ West Africa Center for Cell biology of Infectious Pathogens (WACCBIP), College of Basic and Applied Sciences, University of Ghana, Accra, Ghana. ${ }^{3}$ Epidemiology Department, Noguchi Memorial Institute for Medical Research, University of Ghana, Accra, Ghana.

${ }^{4}$ School of Public Health, University of Ghana, Accra, Ghana. ${ }^{5}$ National Malaria Control Program, Accra, Ghana.

Received: 11 July 2019 Accepted: 21 November 2019

Published online: 02 December 2019

\section{References}

1. World Health Organization. World malaria report 2018. Geneva: World Health Organization; 2018.

2. Program NMC. 2017 Annual Report. Ghana: Ghana Health Services; 2018.

3. Bousema T, Okell L, Felger I, Drakeley C. Asymptomatic malaria infections: detectability, transmissibility and public health relevance. Nat Rev Microbiol. 2014;12(12):833-40.

4. Lindblade KA, Steinhardt L, Samuels A, Kachur SP, Slutsker L. The silent threat: asymptomatic parasitemia and malaria transmission. Expert Rev AntiInfect Ther. 2013;11(6):623-39.

5. Owusu EDA, Brown CA, Grobusch MP, Mens P. Prevalence of Plasmodium falciparum and non-P. falciparum infections in a highland district in Ghana, and the influence of HIV and sickle cell disease. Malar J. 2017;16(1):167.

6. Williams O, Meet S, Abeku T, Baba E, Brownlow K, Chilundo B, et al. Malaria: country profiles. London: Department for International Development; 2011.

7. Haworth J. The global distribution of malaria and the present control effort. Malaria - Principle and Practice of Malariology. Edited by: Wernsdorfer WH, McGregor IA. Edinburgh: Churchill Livingstone, 1988;2:1379-420.

8. Browne EN, Frimpong E, Sievertsen J, Hagen J, Hamelmann C, Dietz K, et al. Malariometric update for the rainforest and savanna of Ashanti region, Ghana. Ann Trop Med Parasitol. 2000;94(1):15-22.

9. Boudin C, Robert V, Verhave JP, Carnevale P, Ambroise-Thomas P. Plasmodium falciparum and P. malariae epidemiology in a west African village. Bull World Health Organ. 1991;69(2):199-205.

10. Trape JF, Rogier C, Konate L, Diagne N, Bouganali H, Canque B, et al. The Dielmo project: a longitudinal study of natural malaria infection and the mechanisms of protective immunity in a community living in a holoendemic area of Senegal. Am J Trop Med Hyg. 1994;51(2):123-37.

11. Faye FB, Spiegel A, Tall A, Sokhna C, Fontenille D, Rogier C, et al. Diagnostic criteria and risk factors for Plasmodium ovale malaria. J Infect Dis. 2002; 186(5):690-5.

12. Collins WE, Jeffery GM. Plasmodium ovale: parasite and disease. Clin Microbiol Rev. 2005;18(3):570-81.

13. Zimmerman PA, Ferreira MU, Howes RE, Mercereau-Puijalon O. Red blood cell polymorphism and susceptibility to Plasmodium vivax. Adv Parasitol. 2013;81:27-76.

14. Niangaly A, Gunalan K, Ouattara A, Coulibaly D, Sa JM, Adams M, et al. Plasmodium vivax infections over 3 years in Duffy blood group negative Malians in Bandiagara, Mali. Am J Trop Med Hyg. 2017;97(3):744-52.

15. Bernabeu M, Gomez-Perez GP, Sissoko S, Niambélé MB, Haibala AA, Sanz A, et al. Plasmodium vivax malaria in Mali: a study from three different regions. Malar J. 2012;11(1):405.

16. Oboh MA, Badiane AS, Ntadom G, Ndiaye YD, Diongue K, Diallo MA, et al. Molecular identification of Plasmodium species responsible for malaria reveals Plasmodium vivax isolates in Duffy negative individuals from southwestern Nigeria. Malar J. 2018;17(1):439.

17. World Health Organisation. Guidelines for the Treatment of Malaria. 3rd ed. Geneva: WHO Guidelines Approved by the Guidelines Review Committee; 2015.

18. World Health Organization. A framework for malaria elimination. Geneva: World Health Organization; 2017.

19. Mueller I, Zimmerman PA, Reeder JC. Plasmodium malariae and Plasmodium ovale-the 'bashful'malaria parasites. Trends Parasitol. 2007;23(6):278-83. 
20. Zimmerman PA, Mehlotra RK, Kasehagen LJ, Kazura JW. Why do we need to know more about mixed Plasmodium species infections in humans? Trends Parasitol. 2004;20(9):440-7.

21. World Health Organization. Malaria rapid diagnostic test performance: results of WHO product testing of malaria RDTs: round 6 (2014-2015). 2015.

22. Ghana Health Service. Akwapim South District. 2014.

23. Ndong IC, Okyere D, Enos JY, Amambua-Ngwa A, Merle CSC, Nyarko A, et al. Challenges and perceptions of implementing mass testing, treatment and tracking in malaria control: a qualitative study in Pakro sub-district of Ghana. BMC Public Health. 2019:19(1):695.

24. NMCP. 2017 Annual Report. Ghana: Ghana Health Services; 2018.

25. Abagna HB, Acquah FK, Okonu R, Aryee NA, Theisen M, Amoah LE. Assessment of the quality and quantity of naturally induced antibody responses to EBA175RIII-V in Ghanaian children living in two communities with varying malaria transmission patterns. Malar J. 2018;17(1):14.

26. Amoah LE, Opong A, Ayanful-Torgby R, Abankwa J, Acquah FK. Prevalence of G6PD deficiency and Plasmodium falciparum parasites in asymptomatic school children living in southern Ghana. Malar J. 2016;15(1):388.

27. Snounou G, Viriyakosol S, Jarra W, Thaithong S, Brown KN. Identification of the four human malaria parasite species in field samples by the polymerase chain reaction and detection of a high prevalence of mixed infections. Mol Biochem Parasitol. 1993;58(2):283-92.

28. Ghana Health Services NMCP. 2014 Annual Report. 2015.

29. Ghana Health Services NMCP. 2010 Annual Report. 2010.

30. Ghana Health Services NMCP. 2015 Annual Report. 2015.

31. Bousema JT, Drakeley CJ, Mens PF, Arens T, Houben R, Omar SA, et al. Increased Plasmodium falciparum gametocyte production in mixed infections with P. malariae. Am J Trop Med Hyg. 2008;78(3):442-8.

32. Yman V, Wandell G, Mutemi DD, Miglar A, Asghar M, Hammar U, et al. Persistent transmission of Plasmodium malariae and Plasmodium ovale species in an area of declining Plasmodium falciparum transmission in eastern Tanzania. PLoS Negl Trop Dis. 2019;13(5):e0007414.

33. Ayanful-Torgby R, Quashie NB, Boampong JN, Williamson KC, Amoah LE. Seasonal variations in Plasmodium falciparum parasite prevalence assessed by varying diagnostic tests in asymptomatic children in southern Ghana. PLoS One. 2018;13(6):e0199172

34. Adjah J, Fiadzoe B, Ayanful-Torgby R, Amoah LE. Seasonal variations in Plasmodium falciparum genetic diversity and multiplicity of infection in asymptomatic children living in southern Ghana. BMC Infect Dis. 2018;18(1):432.

35. Tiedje KE, Oduro AR, Agongo G, Anyorigiya T, Azongo D, Awine T, et al. Seasonal variation in the epidemiology of asymptomatic Plasmodium falciparum infections across two catchment areas in Bongo District, Ghana. Am J Trop Med Hyg. 2017;97(1):199-212.

36. Obare P, Ogutu B, Adams M, Odera JS, Lilley K, Dosoo D, et al. Misclassification of Plasmodium infections by conventional microscopy and the impact of remedial training on the proficiency of laboratory technicians in species identification. Malar J. 2013;12:113.

37. Ba AK, Sanou I, Kristiansen PA, Sangare L, Ouedraogo R, Ouattara K, et al. Evolution of meningococcal carriage in serogroups $X$ and $Y$ before introduction of MenAfriVac in the health district of Kaya, Burkina Faso. BMC Infect Dis. 2014;14:546.

38. Plewes K, Leopold SJ, Kingston HWF, Dondorp AM. Malaria: What's new in the Management of Malaria? Infect Dis Clin N Am. 2019;33(1):39-60.

39. Lo E, Nguyen $K$, Nguyen J, Hemming-Schroeder E, Xu J, Etemesi $H$, et al. Plasmodium malariae prevalence and csp gene diversity, Kenya, 2014 and 2015. Emerg Infect Dis. 2017;23(4):601-10.

40. Lin JT, Saunders DL, Meshnick SR. The role of submicroscopic parasitemia in malaria transmission: what is the evidence? Trends Parasitol. 2014;30(4):183-90.

41. Luise D, Dona D, Visentin F, Marini G, Giaquinto C, Cattelan A. Comparing imported malaria in adults and children presenting to an Italian teaching hospital: a 10-year retrospective study. Travel Med Infect Dis. 2017;17:56-61.

42. Grandesso F, Nabasumba C, Nyehangane D, Page AL, Bastard M, De Smet $M$, et al. Performance and time to become negative after treatment of three malaria rapid diagnostic tests in low and high malaria transmission settings. Malar J. 2016;15(1):496

43. Kyabayinze DJ, Tibenderana JK, Odong GW, Rwakimari JB, Counihan H. Operational accuracy and comparative persistent antigenicity of HRP2 rapid diagnostic tests for Plasmodium falciparum malaria in a hyperendemic region of Uganda. Malar J. 2008;7:221.

44. Iqbal J, Siddique A, Jameel M, Hira PR. Persistent histidine-rich protein 2, parasite lactate dehydrogenase, and panmalarial antigen reactivity after clearance of Plasmodium falciparum monoinfection. J Clin Microbiol. 2004; 42(9):4237-41.

45. Plucinski MM, Dimbu PR, Fortes F, Abdulla S, Ahmed S, Gutman J, et al. Posttreatment HRP2 clearance in patients with uncomplicated Plasmodium falciparum malaria. J Infect Dis. 2018;217(5):685-92.

46. World Health Organization. False-negative RDT results and implications of new reports of $P$. falciparum histidine-rich protein 2/3 gene deletions. 2016.

47. Amoah LE, Abankwa J, Oppong A. Plasmodium falciparum histidine rich protein-2 diversity and the implications for PfHRP 2: based malaria rapid diagnostic tests in Ghana. Malar J. 2016;15(1):101.

48. Gillet P, Mori M, Van Esbroeck M, Van den Ende J, Jacobs J. Assessment of the prozone effect in malaria rapid diagnostic tests. Malar J. 2009;8:271.

49. Freed LA, Cann RL. DNA quality and acuracy of avian malaria PCR diagnostics: a review. Condor. 2006;108(2):459-73.

50. World Health Organization. WHO Evidence Review Group on Malaria Diagnosis in Low Transmission Settings. Geneva: WHO; 2014.

51. Dinko B, Oguike MC, Larbi JA, Bousema T, Sutherland CJ. Persistent detection of Plasmodium falciparum, P. malariae, P. ovale curtisi and P. ovale wallikeri after ACT treatment of asymptomatic Ghanaian schoolchildren. Int J Parasitol Drugs Drug Resist. 2013;3:45-50.

52. Williams J, Njie F, Cairns M, Bojang K, Coulibaly SO, Kayentao K, et al. Nonfalciparum malaria infections in pregnant women in West Africa. Malar J. 2016;15:53.

\section{Publisher's Note}

Springer Nature remains neutral with regard to jurisdictional claims in published maps and institutional affiliations.
Ready to submit your research? Choose BMC and benefit from:

- fast, convenient online submission

- thorough peer review by experienced researchers in your field

- rapid publication on acceptance

- support for research data, including large and complex data types

- gold Open Access which fosters wider collaboration and increased citations

- maximum visibility for your research: over $100 \mathrm{M}$ website views per year

At BMC, research is always in progress.

Learn more biomedcentral.com/submissions 